\title{
Negative incentives and sustainability in the amazonian logging industry
}

Incentivos negativos promovem uma indústria madeireira sustentável? Aprisionamento da indústria madeireira na Amazônia

\begin{abstract}
This paper investigates the existence of lock-in of low technology and high environmental impact on Brazilian Amazon logging industry. The research employed evolutionary economics as a theoretical basis, especially the concept of technological trajectories. The duality of decisions involving logging - conventional logging (CL) versus reduced-impact logging (RIL) - was studied. An agent-based simulation model - in which decision-making under bounded rationality is based on a genetic algorithm was implemented in Java programming language. Results demonstrate the existence of lock-in, producers aversion to risks, greater operational efficiency of sustainable logging, and benefits derived from a policy of environmental bonuses, both in economic and ecological terms.
\end{abstract}

\section{Keywords}

logging industry; bounded rationality; agentbased simulation; reduced-impact logging; evolutionary economics.

JEL Codes B52; C63; Q23.
Hilder André Bezerra Farias

Universidade Federal do Pará

Sérgio Luiz de Medeiros Rivero

Universidade Federal do Pará

Márcia Jucá Teixeira Diniz

Universidade Federal do Pará

\section{Resumo}

O presente texto investiga a existência de um lock-in, ou aprisionamento, de baixa tecnologia $e$ alto impacto ambiental na indústria madeireira na Amazônia Brasileira. A pesquisa teve como base teórica a Economia Evolucionária, especialmente a noção de trajetória tecnológica. Foi estudada a dualidade de decisões envolvendo a exploração madeireira, divididas entre exploração convencional (EC) e de impacto reduzido (EIR). Um modelo de simulação baseado $\mathrm{em}$ agentes em que a tomada de decisão sob racionalidade limitada ocorre segundo um algoritmo genético foi elaborado na linguagem de programação Java. Os resultados apontam para a existência do lock-in, para a aversão dos produtores a riscos, para maior eficiência operacional da exploração sustentável e para os beneficios oriundos de uma política de bônus ambiental, tanto em termos econômicos quanto ecológicos.

\section{Palavras-chave}

indústria madeireira; racionalidade limitada; simulação baseada em agentes; exploração de impacto reduzido; economia evolucionária.

Códigos JEL B52; C63; Q23. 


\section{Introduction}

The central theme of the present work is the qualitative change in the logging industry in the Legal Amazon region of Brazil and, more specifically, understanding the technological transition in the sector, such that it moves away from a probable lock-in of low technology and high environmental impact associated with this industry in the region. This article arose from a desire to understand how technical change in this industry develops; however, before proposing such a transition, it was necessary to verify the existence and causes of possible technological lock-in ${ }^{1}$ - initially understood as a difficulty in moving away from the current technological regime, regardless of whether it is more profitable or sustainable, as a result of incentives in favor of the current technological regime and at the expense of new or already known technological alternatives. Thus, throughout the text, based on the methodology defended, what is intended is the resolution of the following question: is there lock-in of low technology and high environmental impact in the region?

The objective during this study preparation, which resulted in the present discussion, was the construction of an agent-based simulation model. The model's purpose was to verify - based on parameters discussed by other authors studying the theme - the view about the existence of a type of lock-in surrounding an outdated technology (with low profitability and high environmental impact) to support future works that will adopt a more normative aspect. In other words, the goal of the study is to support possible measures - in particular by the public entity - to facilitate the technological transition in the region towards a sustainable standard.

The results obtained corroborate the views previously presented in the literature on the subject, not only regarding the existence of the previously mentioned lock-in but also its causes. Thus, the observation is mainly the indifference of timber consumers regarding the superior quality of timber extracted sustainably, in addition to the higher costs of this new form of forest logging and the low level of control and actions against the illegality of the logging industry. Characteristics of the region make it impossible to rule out the existence of lock-in of low technology, profitability, and high environmental impact for the sector in the region. 
The investigation of the present work is partly justified by the importance of the region (in local and global terms), which, for example, contains $20 \%$ of the planet's drinking water, and the urgency of measures to mitigate the loss of forest coverage, which is already approximately $80 \%$ of the original coverage (Assunção; Gandour; Rocha, 2013). Therefore, the goal is to evaluate attempts to encourage a more sustainable logging industry in the Brazilian Amazon and possible obstacles to these attempts, which could also help reduce the expansion of deforested areas - such as those in which the forest is converted into another type of land cover or when the coverage area provided by trees decreases below $10 \%$ of the original area (Lambin; Geist; Lepers, 2003).

The importance of the present work - which seeks to highlight the problem of technological lock-in surrounding conventional logging and even illegal practices - is the preservation of timber stocks of the forest, especially with regard to the ecosystem services it provides: maintenance of high biodiversity, climate regulation, carbon storage, livelihood and survival for millions of people, and, increasingly, food production (Coe et al., 2013).

In addition to this introduction, this text includes the following: a literature review section that clarifies the relationship between evolutionary economics and logging; a methodological section presenting the model formalization and implementation, in addition to the identification of elements related to the agent-based simulation; a results section, in which the simulation results presented; a discussion, in which results are contextualized according to the literature on the subject; and, finally, a conclusion, which provides greater clarification about the article.

\section{Literature review}

Regarding the characteristics of each type of management to be analyzed as an option for the timber logging agents modeled in this present article, it is useful to conceptualize the two possible strategies. To understand the difficulty of a technological transition or lock-in of a conventional technique, it is necessary to understand how the new technology known as reduced-impact logging (RIL) is defined. For the purposes of this article, RIL will be considered mainly with respect to its lower impact on the 
environment. The variables analyzed to quantify this impact are better detailed in the methodological section of the article.

RIL is a forest logging technique that involves particularities regarding how producers extract timber from the forest. Among these characteristics are the following: planning of routes for removing the timber, control and planning of cuts and the area affected by the falling trees, and reduction in damages caused to the soil and other trees in the area where the cutting is performed.

RIL also involves aspects of compliance with legal standards for minimum cutting diameter, rare species, tree seed retention, maximum cutting intensity, stream preservation, protection against fires, and wildlife preservation. Other aspects of RIL implementation include inclusion actions; construction of roads for the removal of cut trunks; use of directional logging techniques; minimization of heavy machinery usage; direct control of degradation monitoring, as in the case of fires; and strengthening the role of conservation in the granting of property rights (Boscolo; Vincent, 2000; Coe et al., 2013; Sist; Ferreira, 2007; Zarin et al., 2007).

The alternative with the greatest impact is the so-called conventional logging (CL). CL is performed without planning and is considered as environmentally worse than RIL because it does not have all the considerations already mentioned. This creates a context of pressure to increase best forest practices, in the ecological sense. This context reinforces the importance of understanding how $\mathrm{CL}$ is the predominant default decision of producers in the Amazon and which aspects contribute to the still very limited diffusion of RIL (Macpherson et al., 2012). RIL can reduce forest damage from timber harvesting (involving cutting and transport), greenhouse gas emissions, and depletion of the forest's carbon stock. RIL also favors maintenance of biodiversity in the forest (Boscolo; Vincent, 2000; Coe et al., 2013; Valle et al., 2007; Zarin et al., 2007).

To understand the continuing usage of CL despite the better environmental response from RIL techniques, it is necessary to understand evolutionary economics concepts regarding the development process of economic actions in a given time and space.

Considerations on evolutionary economics are usually related to the notion of strategy incorporated in the productive process and its characteristic of selecting new techniques and methods of resource use that guarantee greater competitiveness for a firm. We refer to Schumpeter (1997), 
who, in his Theory Of Economic Development from 1911, shows us how business innovations boost economic expansion, whether they are innovations in terms of services, consumer markets, raw materials, or (but not only) new products.

Advancing in the theme of strategy, understanding the role of innovations is essential for understanding the economic relations in a dynamic context (of transformation). Therefore, the contributions of the so-called neo-Schumpeterians or theorists of the so-called evolutionary economics (as they will be referred to in this present work) - for example, Giovanni Dosi, Richard Nelson, and Sidney Winter, in their primordial models are important.

Regarding the contribution to the present text, one can observe considerations that learning and discovery processes are imperfect. In other words, there is the presence of both error as a learning factor and selection mechanisms, on the other hand, which would function similarly to biological evolution. More specifically, there are selection units (technologies), mechanisms, and selection criteria (e.g., the institutional and enforcement or consumer market responses to the adoption of a new technology), and adaptation and variation criteria (agents capable of experimenting and discovering new ways of behaving, based on their behavioral definitions within the model); consequently, the rationality of the agents is limited - both society and the economy learn and achieve better results from experience, not from the innate discovery of equilibrium (Dosi; Nelson, 1994).

The evolutionary economics topics that favor a deeper understanding of a possible lock-in surrounding a technology, despite the existence of another, include the notions of trajectory and technological paradigm, lockin and trajectory dependency, and bounded rationality itself.

A technological paradigm is understood as the perspective, the model, the standard, and the manner in which one acts regarding progress. Its notable characteristic is its aspect of excluding its alternatives, which involves a preceding process of paradigm selection. The technological trajectory represents a pattern of activity considered to be "normal" - according to Kuhn's meaning - that is reproduced across the domain of a certain technology (Dosi, 2006).

The concepts of trajectory dependence and technological lock-in should not be understood separately. The first term is related to an increase in the 
use of a technology, which makes it better compared with its alternatives. Based on a dynamic of scale returns and better appropriation of this technology through its learning, the concept considers the processes of historical formation as relevant, such that when considering that technological evolution within a given trajectory generally presents a high degree of irreversibility, it is possible to think that in these trajectories, there is usually a lock-in or a difficulty of moving away from the dominant technological regime, such as that of $\mathrm{CL}$ in this article. Thus, the more specific implication of trajectory dependence for the present work is that of technological lock-in (Dosi; Nelson, 1994; Van Den Bergh et al., 2006).

The conceptualization involving bounded rationality refers to the exchange of the neoclassical premise of agents of maximizing rational behavior for a more realistic profile, upon understanding that these agents are not fully informed and do not know in advance all the possibilities during their decision-making. They act based on routines, heuristics (usually a method created aiming at the solution of a certain type of problem), and their past experiences. Such an assumption would also respond through the dynamics of preference change, such that policy efforts aimed at encouraging the highest degree of sustainability in the industry may not be efficient owing to a lack of effort in disseminating relevant information for purchasing decisions by consumers (who are unknown a priori) (Faber; Frenken, 2009; Van Den Bergh et al., 2006).

From the definitions already observed, with respect to the characteristics of both CL and RIL, and from the perspective of lock-in, it is possible to understand the hypothesis that guides the research within which this article is inserted: that in the Brazilian Amazon, there may be lock-in of low technology, with the outdated techniques of CL for timber production, which prevents widespread diffusion of RIL.

There are additional hypotheses - which will be tested, based on the methodology presented - that this technical lock-in may arise from the apparent lower costs of CL; low control of the use of techniques that are not compliant with legislation; and non-perception, by consumers, of the difference of timber extracted in an environmentally friendlier manner - in other words, consumers are not willing to pay more for wood derived from RIL. This hypothesis will be better explored in future works, which will involve mechanisms that help in the transition from CL standard to RIL standard. 
There are indications that reinforce - even before the methodological treatment - the possibility of proving these hypotheses. First, it is understood that profits from illegal exploitation, or that performed with little added technology, are apparently greater than those derived from RIL, which indicates that the timber market in the tropics is guided by the perception of low extraction costs, which favors logging that does not necessarily satisfy current legislation (Karsenty, 2010).

In this context of higher profitability associated with illegal logging or no commitment to legality, which is motivated by the differential between low costs of minimal added technology and international prices of wood, costs for training and implementation of RIL and significant reduction in the net present value (NPV) of current timber cuttings, factors that increase the cost differential between unplanned logging and RIL.

In fact, rules are not being followed, or are only partially followed, and their monitoring is very restricted in the Brazilian Amazon, especially because it is very costly to the government - this generates a context of low perception of the existence of actions for controlling the illegality, and these actions are not in fact regularly conducted (Amacher; Koskela; Ollikainen, 2007).

Thus, fines for non-compliance with logging regulations would not consist of a real disincentive for illegal logging. However, this is something that can be reversed, given that a trend of risk aversion by timber producers is observed, which would make it possible to contain the expansion of illegal practices with better enforcement; otherwise, only the market conditions would remain (price and discount rate for the sector) to guide the technological choice, which would not move to an RIL scenario, owing to the barrier of higher costs in the absence of the perception that such additional costs would generate a differentiated product that is recognized as more valuable by consumers of the wood in the absence of a reward commensurate with the increase in costs. In the evolutionary sense, the users of the forest logging standards (CL and RIL) may not perceive the advantage of using the new logging standard (RIL) because its complementarities are not be observed due to the absence of the process of scale gains associated with its adoption (Dosi; Nelson, 1994).

There are, however, indications that application of fines (or increases in the amounts expected to be paid) would be associated with reduction of deforestation in risk-aversion scenarios because a greater likelihood of 
being fined or a greater amount to be paid represents a risk of incurring in higher production costs, which undermines the main appeal of illegal logging. Notably, in the Brazilian Amazon, one can argue about the role of DETER (Real-Time Deforestation Detection System in the Legal Amazon Region), which was able to reduce deforestation activities by up to $75 \%$ after its implementation. This, in turn, enabled the association of deforestation with the agents' risk posture, given that the increase in the capacity of IBAMA (Brazilian Institute of Environment and Renewable Natural Resources) to identify and address deforestation activity - and thus apply sanctions - was reflected in the increase in the reaction to the risk of sanctions, thus creating deforestation reduction behavior (Amacher; Koskela; Ollikainen, 2007; Assunção; Gandour; Rocha, 2013).

In addition to this introductory component of the relationship between the producer's costs and government action, in the discussion section, there is a more comprehensive presentation of aspects related to the nonadoption of RIL in the Legal Amazon, which pass through a process of reflection after exhibition of the results obtained from the proposed simulation model. The following section formally details this model and indicates how its implementation was performed, in addition to demarcating and justifying elements that corroborate the use of simulation as a tool for understanding the reported problem.

\section{Methodology}

Given the initial concept about the elements of forest logging techniques and the action-taking behavior of loggers, we move now to the simulation proposal using game theory (the central methodological part of this project). The model is an adapted form of the model of the timber producers' behavior, which follows a pattern of maximization of net present value, as in Boscolo and Vincent (2000) and Macpherson et al. (2010) models.

Thus, as in Boscolo and Vincent (2000), the model takes into account forest growth, according to which

$$
y_{\mathrm{t}+\theta}=\mathrm{G}_{s}\left[y_{t}-h_{t}-d_{\mathrm{st}}\right]+\mathrm{r}_{\mathrm{st}}
$$

where vector $y_{t}$ corresponds to the number of live trees at time $t$ of the spe- 
cies group $i(=1, \ldots, \mathrm{m})^{2}$ and group of size $j(=1, \ldots, \mathrm{n})^{3}$ in one hectare of forest; $h_{t}$ refers to trees cut at time $t$ (a vector of size mn by 1 ); $s$ represents the cutting regime; $d_{t}$ represents the damage caused by the cutting in accordance with the management at time $t$ (being a vector of size $\mathrm{mn} \times 1$ ); and $r_{s t}$ is a recruitment parameter, which corresponds to the number of new trees that appear within the analyzed hectare. Finally, $G_{s}$ is the transition matrix of trees, which may die, change, or remain in the same size group.

Moving then to the contributions of Macpherson et al. (2010), these authors show that the presence of a minimum diameter cutting restriction can be represented by

$$
h_{\mathrm{ij}}=0, j \leq 4
$$

with the measurement of the damages per technological regime based on

$$
d_{\mathrm{st}}=\left(\sum_{\mathrm{i}=1}^{m} \sum_{\mathrm{j}=1}^{n} h_{\mathrm{ij}}\right) D_{s} y_{t}
$$

where "s" is assumed to be an index with value of 1 for IL, 2 for CL, and 0 when no cutting is performed; $d_{s}$ corresponds to residual damage for regime $s$; and $D_{s}$ is the set of damage parameters ( $m$ by $n$ ).

The variable $w$ refers to the adoption of RIL, which may be total, partial, or zero, such that $w \in[0,1]$.

However, in the proposed simulation, we can only have values of 0 or 1 , representing - in the strategic decision-making - a predatory or sustainable logging profile, respectively. Likewise, the illegal adoption of RIL which represents the use of techniques that do not correspond to the legal standard of RIL use - can be understood according to a parameter in the following form:

$$
w_{\text {illegal }} \in[0,1]
$$

2 The data for the species studied were obtained in the region of Paragominas, Pará state where the species studied in the municipality are divided into 5 groups, namely pioneering species, light-demanding species, intermediate species, shade-tolerant species, and emerging species (Macpherson et al., 2012).

3 The size groups are divided according to the stem diameter at breast height, and they range in value from 10 to $20 \mathrm{~cm}$ for the group of index $j=1,20$ to $30 \mathrm{~cm}$ for group 2, and so on, with group $j=10$ including all observations greater than or equal to $100 \mathrm{~cm}$. However, the model uses only the groups above $50 \mathrm{~cm}$, via restriction (3.2), which results in 6 size groups and 5 species groups, with a total of 30 categories. 
The model of Macpherson et al. (2010) provides the waste parameters ${ }^{4}-$ which refer to the percentage of wood that has already been collected but will not be useful for commercialization - for each technological regime:

$$
\begin{aligned}
& \text { waste }_{1}=0.042 \\
& \text { waste }_{2}=0.261
\end{aligned}
$$

The analysis of legality starts from a cutting limit and considers that starting from a volume commercialized per tree $\Psi$, there will be an illegal harvest $\Psi^{\prime} h$ that will correspond to

$$
\begin{aligned}
& h_{\text {illegal }}=\Psi^{\prime} \mathrm{h}-30 \mathrm{se} \Psi^{\prime} \mathrm{h}>30 \mathrm{~m}^{3} / \mathrm{ha} \\
& h_{\text {illegal }}=0 \text { se } \Psi^{\prime} \mathrm{h} \leq 30 \mathrm{~m}^{3} / \mathrm{ha}
\end{aligned}
$$

Owing to the legal cutting restrictions per area (Zarin et al., 2007),

$$
h_{\text {illegal }} \in[0,11]
$$

Advancing in terms of enforcement and illegality, an illegality factor " $x$ " is considered, together with a probability that this behavior is detected, which is represented by $\theta(x)$ and measured as

$$
\theta(x)=1 / 1+e^{-x}
$$

in which

$$
\mathrm{x}=\mathrm{h}_{\text {illegal }}+\eta \mathrm{w}_{\text {illegal }}-\tau
$$

with the constants

$$
\eta, \tau=11
$$

It is from these initial considerations that one then arrives at the economic model for optimization of NPV. Such model considers the existence of a discount rate:

4 Note here that the use of CL is strongly associated with a high rate of loss of wood already collected. 


$$
\delta=1 / 1+r
$$

with " $r$ " being a discrete discount rate (it has the value of $9.5 \%$ p.a. in the simulation). The model employs the following variables: prices $P_{i j}{ }^{5}$; variable costs per cutting regime vcijs; and fixed costs per cutting regime $F_{c s}$.

The following is the expected profit:

$$
E(\pi)=\sum\left[\left(1-\text { waste }_{w}\right) P_{\mathrm{ij}} h_{\mathrm{ij}}-\mathrm{vc}_{\mathrm{ijw}} h_{\mathrm{ij}}\right]-F_{\mathrm{cw}}-\mathrm{f} \theta(x)
$$

with $\mathrm{f} \theta(x)$ representing the value of the fine in the case of capture. The $N P V$ expected for $T$ periods of logging is

$$
E(\mathrm{NPV})=\mathrm{E}(\pi) \sum_{\mathrm{t}=0}^{T} \delta^{t}
$$

It is worth noting that all of these choices are limited to a set of restrictions - economic restrictions, legal restrictions, and the amount of timber available to be logged in the area - as summarized in Mapcherson et al. (2012), although we discard the hypothesis of different perceptions of economically exploitable wood associated with each logging regime.

It is further clarified that the parameters used follow those listed in Macpherson et al. (2010), in terms of the wood price (which varies according to the group's size and species but remains constant in all simulations), which is considered to be the same throughout the period and for all producers (who are considered as price receivers), with fixed and variable cost data also taken from the mentioned authors, differentiated according to the logging technique practiced. Growth parameters are the same as those in Boscolo and Vincent (2010).

The information presented was used to sustain the implementation of an agent-based simulation model employing Java programming language, for the purpose of understanding the relationships of companies in the sector, the role of innovations in the production chain of timber industries, and the role of the State in directing the sector towards a more sustainable trajectory. For a clearer understanding of what is proposed here, a brief

5 Because the market is considered to be exogenous for the model, the prices are taken as constants, since this work scope does not include the understanding of the effects of relative price changes; that is, although there is an array of different prices, it remains constant throughout the whole simulation. 
exposition of concepts and formulations related to the use of simulation as a form of economic modeling is justified.

To simplify the model, each producer has only one management strategy, i.e., complete CL or RIL, and only the degree of legality in the implementation of the RIL is varied. Consequently, in the present work, the possibility of legal practice of CL is not studied, which can be complemented in later works. The dynamic approach embodied in the model helps to understand the responses of forest logging to different forest management regimes and the intensity of this logging in the area. Therefore, it is necessary to understand environmental constraints, the role of change in legislation, and adaptation issues due to a change of strategy in forest logging decisions (Macpherson et al., 2012; Yousefpour; Hanewinkel, 2009).

The primary potential benefits of this type of approach - which is within the scope of agent-based computational economics (ACE) - are the characteristic of these models, which are based on the interaction among adaptive agents, which include a wide range of weighting (and relationship) elements with economic, social, and environmental entities; it is these agents that will provide the observable characteristics of the model (unlike external aggregation). The group of agents itself will provide the information that will enable inferences to be made about the results from the theoretical point of view (Tesfatsion, 2002).

The use of agent-based simulation models enables the creation of systems that are reactive to environmental stimuli, given that these agents have rules for decision-making and the types of attitudes that must be taken, such that they have initial definitions guiding their behavior and their adaptation, based on economic, social, and environmental factors. Thus, the results of these types of models for the specific subject help in understanding (in the aggregate sphere) spatial phenomena and, in the sphere of the agent itself, help in understanding risk aversion during decision-making periods (Gilbert; Terna, 2000; Lambin; Geist; Lepers, 2003).

For the decision-making algorithms to represent the boundary of loggers' rationality, genetic algorithms were used. These algorithms employ an analogy with the functioning of biology, inspired by the theory of evolution and natural selection. In this type of algorithm, there is a population of individuals, each with a certain "fitness", which is defined specifically depending on the model (NPV in the specific case here). 
The fittest individuals, or set of decisions, reproduce and generate new individuals that are fit owing to the inheritance of characteristics from the previous generation. This is a process that is repeated over several generations until one generation achieves greater degree of convergence to an adaptation scenario, where individuals or the existing options have a higher degree of desirability according to the model; however, optimization of values is not guaranteed because the initial distribution of possibilities and mutations may never reach a possible optimal value of the model, which would in itself represent the premise of the rationality boundary of agents (Gilbert; Terna, 2000).

One final important consideration regarding the methodological proposal stated here is that of the non-trivial connection between the evolutionary approach and the agent-based simulation, which can be explained even better using the elaboration of Arthur (1991), who starts from the premise that human rationality is limited. Moreover, Arthur (1991) contribution is the clarification of how economic models must be elaborated with this primordial consideration and how the agents of a simulation of reality should be created, by taking as reference real people and how they would actually act, instead of assuming the same idealized behaviors.

More concretely, it can be understood that any algorithm that serves to model economic agents must be thought of as a reproducer of statistically recurrent patterns of human behavior characteristics, including errors and deviations related to human's (bounded) rationality. For the composition of the genes of the genetic decision algorithm, the following were considered: the technological adoption variables (RIL or CL); the degree of illegality of RIL adoption, if adopted; and the cutting values by group of species and size, based on the legal cutting parameter above $50 \mathrm{~cm}$ in diameter at breast height for the stems, which generates a group of 30 other variables to be considered - in total, the chromosomes of the algorithm are composed of 32 genes, and their fitness values are measured through the calculation of the expected NPV (equation 3.8).

The simulation model was executed five times for each scenario, with 300 producers, to reduce the deviations and capture the mean adoption of the sustainable strategy and the expected mean profitability of the sector, over a 90-year horizon, for which the producers' decisions are reviewed annually based on the NPV expected for the next 30 years of logging. The producers' areas are divided into 30 equal parts, and each year, the producer operates, 
logging an area, such that at the end of the period the producer returns to the first plot logged, which may or may not be recomposed, given that the model is a dynamic model for the forest that depends on the decisions of the loggers themselves ${ }^{6}$. Each model year can be summarized as shown in Figure 1.

The cases analyzed were as follows: the default ("Def" in the reference of Figures 2 and 3), in which there is no form of bonus or fines ${ }^{7}$ and the parameters from the literature mentioned are maintained; a scenario involving the existence of recognition of the superior quality of the timber extracted using RIL, and an additional payment for RIL timber of $15 \%$ for all size and species groups (the "BP" case, which may also be an approximation of good practice remuneration policies); the case that can be considered as one of similar amounts of waste in the two logging models, RIL and CL, (the "SW" case - the waste value for RIL is the same as that of CL, i.e., 0.261); and finally, a context in which fines are paid at a lower value $(\$ 100)$ and another in which the value is higher $(\$ 700)$ - the "Lfee" and "Hfee" cases, respectively).

Figure 1 Representation of the model in a time period " $t$ "

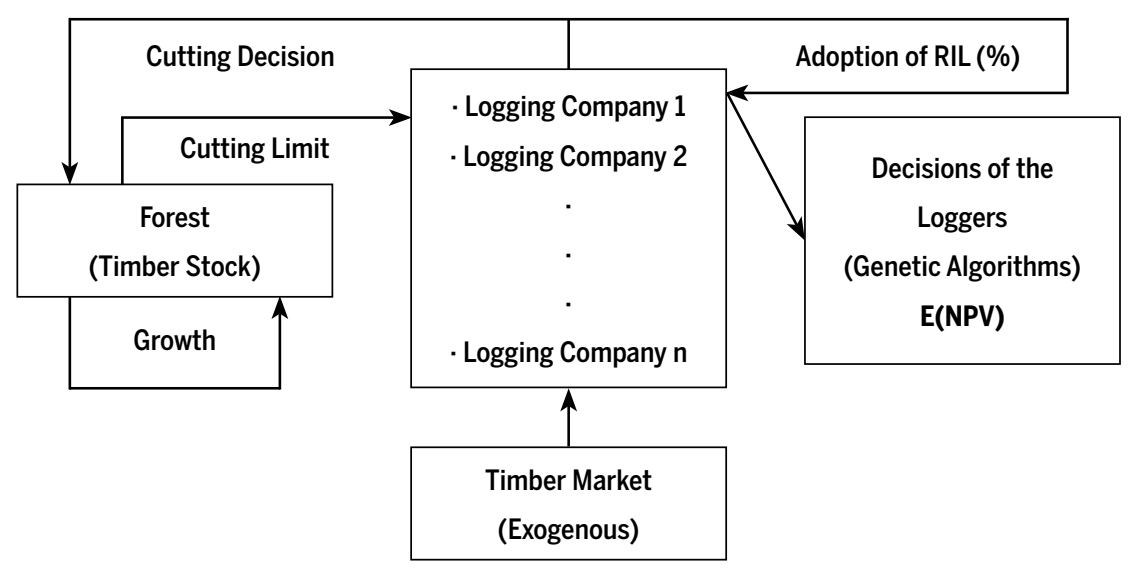

Source: Prepared by the authors.

6 The forest regeneration capacity is - as indicated by the equations - a function of the quantity and diversity available in the area, such that the intensity and type of species logged may compromise - to a greater or lesser degree - the capacity for maintenance and growth of the future stock of timber.

7 The absence of fines is explained by the consideration that the model resembles the current context of low imposition of control mechanisms, since these are imperfectly applied and too costly, as noted in the discussion section. 


\section{Results}

The results obtained from the simulations help to understand the level of existence and/or permanence of the lock-in surrounding a technological logging standard with lower logging quality and greater environmental impacts.

The understanding of the results involves comparing data from the default case to others, which will be analyzed with higher statistical rigor via Table 1 but which can already be interpreted based on the images in this present section. The values observed in the "Adoption Rate" axis refer to the percentage of entrepreneurs who decide to adopt the RIL standard, which in the default case corresponds to an average of $45.54 \%$; that is, in the base scenario, more than half of the agents did not adopt RIL. It is worth considering that this information refers only to the aggregate of the adoption and does not exempt it from illegality, both on the side of the overexploitation of the area and by the use of techniques that do not correspond to the legal standard for use of RIL. However, the value can still be considered representative in terms of technological adoption initiative and probable impacts on the environment.

The only value lower than the default in terms of adoption is the case in which the two exploratory standards are considered as having equal waste, with adoption rate falling to $27.10 \%$. In this scenario, the presence of superior operational efficiency in the RIL case (waste minimizer) is one of the main reasons for its adoption and makes it attractive, as will be better observed in the discussion of the problem in the later section.

On the other hand, the other cases exhibit increased adoption of RIL. They are divided into two groups: one with a bonus for the higher environmental quality owing to its recognition by the demand, the "PB" case, and another with punishment for illegality - "Lfee" and "Hfee". In these scenarios, what can be observed is that the adoption motivated by a $10 \%$ bonus on the sale price - which is within the margin that, in the literature, is considered to be viable (Pearce; Putz; Vanclay, 2003) - indicates an adoption rate of $66.90 \%$ and is closer to the "Hfee" case $(71.87 \%)$ - of more prohibitive fines - than the "Lfee" case $(52.66 \%)$.

Additionally, the finding of the impact that the application of fines has on the RIL adoption values reveals the existence of both illegality in scenarios where such control mechanism is absent - thus making more serious the already stated absence of sustainable techniques in these cases 
- and the risk aversion characteristic among agents in the sector.

It should be clarified that in cases of imposing fines for illegality, in addition to the increased adoption effect, what may occur - considering the existence of other sectors for utilization of the capital - is a situation in which the profitability of logging can be more easily surpassed by alternative use of the land, such as for agricultural and cattle-breeding practices. These aspects were not included in the simulation but are relevant, as the discussion section of this article clarifies.

In the case of positive reinforcement of the sector through recognition of the quality derived from RIL, in addition to an increase in the adoption of RIL, there is the improvement in the profitability of the sector, making it more attractive while simultaneously making it possible to improve profitability with the adoption of more sophisticated techniques, which can initiate a more sustainable trajectory for logging in the region, thus providing this industry with possibilities for future scale gains.

The relationship between the adoption rate and the NPV expected for the undertaking in each of the cases can be observed in Table 1. From this table, it can be observed that although the cases of negative incentives may represent progress towards greater adoption of the less predatory technique, they do so in a manner that reduces the profitability of the activity (see "NPV in relation to the default case" column) thus demonstrating that such incentives do not describe real progress in terms of sustainability of the activity, which will be discussed in more detail in the next section.

\section{Figure 2 Boxplot for the adoption of RIL in each simulation scenario}

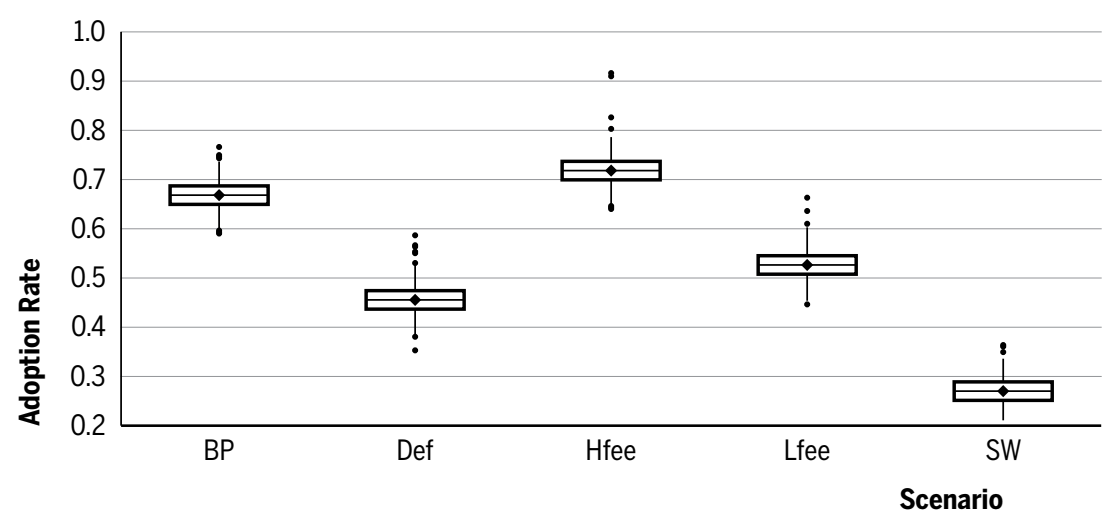

Source: Prepared by the authors. 
Figure 3 Density graphs for the adoption of RIL in each simulation scenario

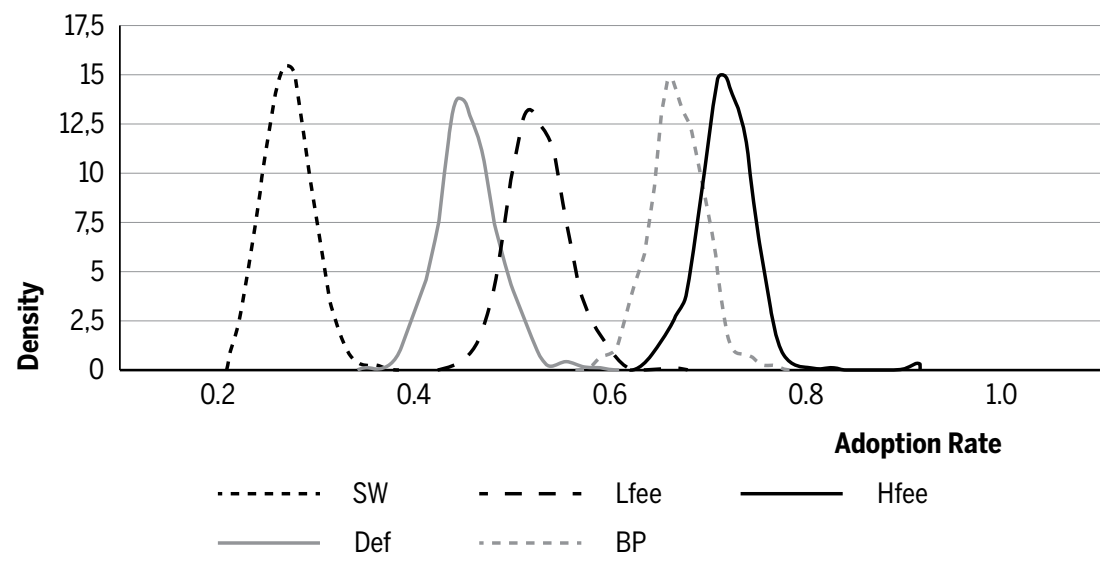

Source: Prepared by the authors.

Table 1 Compilation of results for the simulation model regarding adoption of RIL and NPV

\begin{tabular}{l|r|r|r|r|r}
\hline Scenario & $\begin{array}{r}\text { RIL adoption } \\
\mathbf{( \% )}\end{array}$ & $\begin{array}{r}\text { Standard } \\
\text { deviation RIL } \\
\mathbf{( \% )}\end{array}$ & $\begin{array}{r}\text { Min NPV } \\
\mathbf{( R S )} \\
(\boldsymbol{\alpha}=\mathbf{9 5 \% )}\end{array}$ & $\begin{array}{r}\text { Max NPV } \\
\mathbf{( R \$ )} \\
(\boldsymbol{\alpha}=95 \%)\end{array}$ & $\begin{array}{r}\text { NPV in relation } \\
\text { to the Default } \\
\text { scenario* (R\$) }\end{array}$ \\
\hline Def & 0.4554 & 0.0317 & 3930.853 & 3972.445 & \\
\hline SW & 0.2710 & 0.0250 & 3285.255 & 3322.145 & -647.9489 \\
\hline Lfee & 0.5266 & 0.0303 & 3779.641 & 3829.828 & -146.9144 \\
\hline Hfee & 0.7187 & 0.0312 & 2972.710 & 3055.903 & -937.3424 \\
\hline BP & 0.6690 & 0.0282 & 6595.728 & 6655.173 & 2673.802 \\
\hline
\end{tabular}

Source: Prepared by the author. *All values have a p-value $<2.2 e-16$.

\section{Discussion}

To better understand and contextualize the results, we must consider that studies on the possibility of wide adoption of RIL in the Brazilian Amazon are not incipient - despite being still a current discussion - given the difficulty of progressing in the implementation of this technique in logging ventures in the region. Within the scope of discussions regarding the conciliation of environmental conservation and economic sustainability of the ventures, it is argued that RIL is capable of being both profitable and sustainable while maintaining a substantial part of the carbon stock, bio- 
diversity, and transpiration of the forest. Thus, the timber industry can be developed in an economically efficient manner, thereby achieving greater sustainability in underdeveloped economies.

Additionally, conservation strategies for the Amazon are based around biodiversity and protected areas. However, it is still necessary to think about the economic value of the forest, and RIL reveals that sustainable management can occur even outside protected areas, although the balance between conservation and profitability (where public intervention is necessary) is delicate (Merry et al., 2009).

The discussion in defense of RIL starts from the findings that this logging strategy is profitable for producers and helps to guarantee the future availability of timber for cutting. These gains are associated with greater operational efficiency rather than increased preservation of future timber stocks (Macpherson et al., 2012), which is also one of the results obtained by the simulation performed in the present work. Although it is argued in relation to the possibility of this type of model generating a different configuration in the timber stock, reducing the presence of trees of greater commercial value, it is necessary to understand it in relation to its impact reduction, and quality and cost efficiency in terms of carbon sequestration and operational efficiency, given that a reduction in fixed logging costs would not be expected from CL practice because traditional types of management do not involve good infrastructure planning for production, especially that of roads for the flow of forest production (Boltz; Holmes; Carter, 2003; Boscolo; Buongiorno; Panayotou, 1997; Boscolo; Vincent, 2003).

The present article provides methodological contribution owing to moving away from the analysis of a single agent to understand how the institutional ordering affects a whole set of agents (under the assumptions of bounded rationality and heterogeneity), in addition to addressing scenarios closely linked to the specific discussion for the region, particularly in the case of the real results from negative incentives for the timber industry. It also contributes theoretically, owing to corroborating and substantiating the discussion involving institutions and technical change in the industry studied, emphasizing criticisms of the enforcement, and considering policy instruments (especially the price bonus mentioned).

It can be observed in the literature that one element that hinders the transition of the Legal Amazon region's logging sector to a paradigm of greater technological aggregation and management systems that would 
guarantee greater profitability and sustainability of the system is the weakness of legal enforcement for infractions in the sector in the Legal Amazon region. So, when we design the policies for fines, we are considering their regular enforcement, which may not reflect what actually happens, thus further damaging the results in terms of sustainability, given the understanding that there is no linear relationship between increase in fines and enforcement.

This relationship would occur in part - as addressed by Boscolo and Vincent (2007) - because there is a context of low impact from institutional decisions that lead to a problematic and degrading functioning of the timber industry, thus creating incentives to increase the annual cutting area. Even in cases where a cutting restriction is present, there could be a change in the focus of logging to trees of greater commercial value (which could make them scarce). Some enforcement gaps may become critical points of transposition of interests in favor of predatory logging and the maintenance of conventional techniques, which do not have at their core a concern with sustainable logging of the forest.

Another aspect to be highlighted is discussed in Brito and Barreto (2011) and Pereira et al. (2010), according to whom there is a bias of scarce supervision of human and financial resources for environmental control, which adds to the difficulty in detecting illegal logging and also generates impunity because there is a low level of timber harvested per area of exploitation (with 3 to 7 trees cut per hectare) and a bias of shortages in human resources (on the producer side), specifically a shortage of professionals trained in forest management, which becomes a critical element in the context of forest concessions.

Accordingly, Macpherson et al. (2012) confirmed that current policies do not guarantee the sustainability of the cut - even with the long-term benefits from the implementation of RIL - owing to elements of corruption, government inefficiency, and insecurity regarding the maintenance of property rights (which are essential for long-term planning of managed logging), which are genuine pathways towards illegality.

It is clear that even with a profile of increased adoption of sustainable logging in the Lfee and Hfee cases (see Table 1) compared with the default scenario, the results of the simulation may represent a somewhat "optimistic" world, which indicates that the costs of reducing NPV end up by creating a scenario where the imposition of punitive institutions - with 
a negative incentive structure - could undermine sustainability, both in environmental and economic terms, in addition to being a costly element (from supervision) for the public entity, thus indicating the inefficiency of increasing punishments without there being an offset to benefit good practices (as in BP case).

Although simulations were performed independently (with the criteria altered in each one), it can be observed that the cases that had the best benefits at a low cost, in terms of industry profitability, were those of moderate fines (Lfee) together with bonuses for good practices (with the perception that the product of sustainable origin has a quality differential, as in $\mathrm{BP}$ ) - the scenarios in which the public entity would not have to confront so intensely the cost pressures and human resources difficulties mentioned in this section and therefore are more likely be implemented. All these considerations are necessary to envisage the logging issue as permeated by high-complexity elements.

Similarly, the discussion on the subject in Boscolo and Vincent (2007) also indicates that enforcement may include the depletion of the timber stock, as long as there is a perception of this among producers, which could be accomplished by strengthening legal institutions, having more monitoring, issuing more penalties (which faces restrictions in the Amazon case) and, in particular, having a performance bonus (which could be represented by the BP scenario as an approximation).

When analyzing the context of incentives to reduce illegal logging practices, Conrad et al. (2005) highlighted the particularities and complexity of tropical forests in assessing the different consequences of each incentive mechanism. These authors consider that the high degree of heterogeneity of native forests creates greater cutting complexity, adds different growth rates by harboring differentiated stocks of wood per area, and creates a need to evaluate the determination of economically recoverable cuts. It is necessary to mention here the SW case, where the effect of waste reduction on the cut with RIL is removed, which drastically affects its adoption and the NPV, given that one of the greatest advantages of using the mentioned technique is its sustainable profile of ensuring timber production for long periods, owing to maintenance and greater capacity to recover the exploited stock.

Macpherson et al. (2010) also argue that the cutting of timber causes changes in the flora, such that simple replacement of the timber stock in homogeneous terms (measured simply in $\mathrm{m}^{3}$ of timber) does not necessari- 
ly include recovery of the economic value of the area, i.e., the sustainability of the activity. Advocating in this direction, Fearnside (2010) indicated that imposing the use of RIL does not necessarily affect the portion of illegally logged timber (and its greater collateral damage). Fearnside (2010) also indicated a need for management projects that think deeply about the resilience capacity of the forest and are in realistic terms of participation (by the government and producers), with strict monitoring (going beyond impositions that simply specify the minimum width of the trees for the cut and the minimum periods for cutting cycles). This reinforces the lock-in aspect that surrounds CL, from which there will be no escape without great effort and losses if the only alternative followed is that of negative incentives.

Giving greater emphasis to the role played by society, Ros-Tonen et al. (2008) observed that the complexity of logging in the Legal Amazon region would be restricted not only by the ecosystem heterogeneity but also by social and political characteristics. For the authors, it would be necessary to go beyond simple implementation of RIL, with greater stimulus given to the involvement of local communities, because the ecosystem complexity would coexist with the diverse agents involved in the decisions affecting the forest logging in the Legal Amazon region. Along this line, Brito and Barreto (2011) also made proposals for institutional planning in the region, considering the need to increase the transparency of law application, which must follow a different strategy, prioritizing punishment of the biggest violators.

However, the issue of technological transition is complex in that it goes beyond the discussion of the benefits and reservations of the new technology, and there also remain concerns about the effects that exacerbate lockin surrounding technology that is environmentally more harmful.

Given the narrowness of the methodologically studied scenarios, other elements need to be better elaborated in the present discussion. First, it is important to understand what would motivate the maintenance of traditional logging or the depletion of the area in the case of change in land use.

It is argued that in Brazil, the expansion of livestock and agricultural systems - such as those based on cutting and burning and also soybean expansion - causes changes in land use, specifically through increased deforestation resulting from the link between overexploitation of logging activity and international economic cycles. The forest transformation into pastures and plantation fields is a reality motivated by the possibility of 
gains from the international demand for agroindustrial commodities and from new gains created by markets and the creation of new opportunities, which are accompanied by loss of adaptive capacity, increases in the vulnerability of the affected areas, and generation of changes in social organization (Klimas et al., 2012; Lambin; Geist; Lepers, 2003; Nepstad, D. C. et al., 2008; Nepstad, D. et al., 2009; Valle et al., 2007).

Thus, the imposition of fines for illegal logging, in addition to similar control mechanisms, may represent a risk to the forest because they could both reduce the profitability of logging - which would remove the producers from the sector - and accelerate a possible change in land use, which would eliminate the forest coverage ${ }^{8}$. To reinforce this idea, it may also be considered that the profitability of agriculture, if sufficiently high, will be a barrier to the implementation of the valorization of the standing forest, even when considering risks in terms of costs associated to illegality.

The methodology used is within the context that even with the possibility of sustainable use of the forest, including as a guarantor of income, there remains a lock-in pattern surrounding the technology of conventional logging. We can think of changes in land use as an emergent property of complex adaptive systems - land use is not static but is rather constantly changing as a result of changes in attitudes and feedback derived from the behavior of the agents that act on land use. Thus, adaptive systems are worked on because the presence of expectations can be observed from internal and external conditions of the agents - something that changes their future behavior based on the reality they come to know (Lambin; Geist; Lepers, 2003).

In the set of factors for the system property of revealing patterns of low-sustainability land use, we can consider elements that are not directly in the model but that are already the result of a dynamics observed during the measurement of parameters employed in the methodological treatment conducted. This begins by considering the cost factor, or the differ-

8 It is necessary to clarify in this conjecture that there would be two types of logging: one temporary, of forest suppression, and one perennial, which aims to keep the forest standing by handling the stock from the logging (which occurs in the long term). Whereas the mechanism of fines tends to inhibit temporary logging, perennial logging (which the model addresses) suffers from the negative effect of fines, owing to the reduction in profitability, which stimulates alternative activities from a trade-off between the profitability of this perennial logging and the profitability of farming, which has an initial impulse from deforestation for the release of the areas for economic exploitation and thereafter the pressure from this type of mechanism (fines) against deforestation. 
ence between cutting costs and revenue, with valorization of the wood price, derived from illegal exploitation, which, for being smaller, favors the expansion of illegal logging areas (Gutierrez-Velez; Macdicken, 2008).

It could be argued that forest overexploitation with deteriorating carbon-stocking techniques would still be associated to differences between income from land - in terms of agricultural development - and income from the forest, composed of both forest products and services of the ecosystem provided by the forest, so that the latter would still have to overcome a number of obstacles to become competitive against the former; for example, it would be necessary to overcome weak, poorly defined, and contested property rights and lack of assistance to the communities, which results in firms avoiding investing in better environmental practices.

Additionally, there is an argument about initiatives for internalizing externalities 9 (with the creation of markets for public goods, including forest services), community forest management, reduction of emissions through REDD, and the use of protected areas (Angelsen, 2010; García-Fernández; Ruiz-Pérez; Wunder, 2008; Macpherson et al., 2012).

Analyzing the more traditional economic intervention policies as well, one can see that the sensitivity of better environmental management regimes to the discount applied to the NPV is higher for higher rates, such that in scenarios with very high interest rates, the discount makes it uncompetitive to use environmentally friendlier logging (Boltz; Holmes; Carter, 2003; Pearce; Putz; Vanclay, 2003). Additionally, the use of logging rates - aimed at creating government revenue in tropical forests - may have as a secondary effect the valuation of resources, with the consequent reduction in waste and addition of value to the products, provided that there is control of illegality, given that in addition to the loss of government royalties, illegal logging generates inefficiencies in timber cutting operations, productivity losses, and unemployment (Gutierrez-Velez; Macdicken, 2008; Macpherson et al., 2012).

A final analysis is performed regarding fines and change in land use, which may induce loggers to accelerate the logging and be more selective with the cuts in the areas (to remove trees of higher commercial value

9 This refers to the fact that an externality, which normally results from the interaction between two parties and generates effects to third parties (as in the case of depletion of the diversity, which affects the region as a whole), would be accounted for in the activities that it gave rise to (as in the case of the payment of fines for pollution or reduction in biodiversity). 
more quickly). If fines are too high, they discourage production in areas where there are predominantly trees of lesser commercial value, in addition to discouraging risk-averse producers from investing. What is understood is that the fines could stimulate - in an imperfect enforcement environment, as in the case of the Amazon - faster conversion of forest areas into pastures and plantations because these alternatives are more profitable in terms of future profitability, and the deforestation required for their transition would not pose such a high risk to the decision-maker.

It is not necessary to put aside this type of instrument (as already mentioned); however, it is still incomplete - it needs to be accompanied by measures that decelerate the depletion of the areas (motivated by the enforcement of the rate) (Boscolo; Vincent, 2007). In fact, what is perceived is that all instruments can complement each other, which opens up room for different measures that can work together to reduce illegal deforestation and also progressively improve the logging techniques used in the Brazilian Amazon, with a focus on increasing the profitability of forest products and reducing the impacts on the environment.

\section{Conclusions}

Among the conclusions reached in the present work are the following items:

- The assumption of the existence of a low-technology lock-in with high environmental impact - associated with the propensity for illegality among loggers in the Brazilian Amazon - cannot be ruled out.

- When thinking about the strategic duality of adopting CL and RIL, it can be observed that CL has the advantage of lower costs, whereas RIL has better results in terms of operational efficiency, which favors its adoption, even in institutional contexts that do not favor it in any manner, especially as a result of the reduced waste of extracted wood resulting from RIL.

- Timber producers in the region can be characterized as averse to the risk of fines, and this instrument is capable of reducing the adoption of CL; however, this change would be associated with lower profitability in the sector, which could favor changes in land use in the region to agricultural or cattle production, which would in turn eliminate the forest coverage of the land. 
- The results of the simulation conducted reveal that an environmental bonus, which favors the recognition of the differentiated environmental quality of products derived from sustainable strategies, would generate both greater profitability for the sector and higher values in the case of adoption of RIL.

In general, what is perceived is a need to go beyond simple legal mechanisms of punishment and instead start to embrace the incentive for technical change through policies that involve producers, government agents, and the community, to create control mechanisms and encourage production within legal standards and through a management model that is concerned not only with the profitability and sustainability of economic exploitation but also with the maintenance of timber stocks and forest diversity in the region, which are inseparable for the long-term of the timber industry in the Amazon.

The employed approach has some limitations, which are predominantly related to non-measurement of the environmental quality in the region resulting from the adoption of one or another strategy - an instrument necessary for the argument in favor of a policy measure in the reckoning of an environmental bonus for producers who adopt RIL. Moreover, the results were presented in mean terms for the whole period, which does not allow for analysis of the evolution of the adoption trajectory of RIL in a dynamic context, as was simulated.

Thus, in future work, verification of the environmental quality associated with the context of adopting each logging regime will be conducted, both in terms of carbon stock and forest diversity, to observe the risks of adopting RIL, especially regarding the loss of diversity with accelerated cutting of higher-value trees.

It is also necessary to test the effects of sensitivity to discount rates and changes in relative prices for the timber sector - which are not captured in the current model - because the uncertainty would be due to the inability to know the best cutting alternative (owing to the bounded rationality of the agents).

Additionally, it is important to move away from positive analysis of the sector and move towards a context of simulations that allow analysis of the impacts of economic policies that avoid simple imposition of fines and similar mechanisms of control, to think more clearly about policies 
with an environmental bonus, proposing and testing the impacts of this type of measure, and to observe how it is able to act in the trajectory of the decision-making for the timber industry in the Legal Amazon region.

A final qualification to be made is a defense of the choice for Java programming language as a modeling tool for the simulation used in this text. It was chosen owing to its ease of use and diffusion, in addition to having a library (set of predefined functions) for the implementation of genetic algorithms, the Java Genetic Algorithms Package (JGAP), for understanding the relationships between companies in the sectors, the role of innovations, and the role of the state in conducting economic activity in the region for a more sustainable trajectory. Additionally, Java serves as a basis for simulation platforms based on more robust agents, such as Java applets in Netlogo or with the Repast platform, specifically directed to the construction of agents (Bandini; Vizzari, 2009). It is also noted that the language has a positive future outlook, for being a powerful language, widely used, and for becoming a standard for simulations in the social sciences (Tobias; Hofmann, 2004).

\section{References}

AMACHER, G. S.; KOSKELA, E.; OLLIKAINEN, M. Royalty reform and illegal reporting of harvest volumes under alternative penalty schemes. Environmental and Resource Economics, v. 38, n. 2, p. 189-211, 27 fev. 2007. Disponível em: <http://link.springer.com/10.1007/ s10640-006-9070-7>. Acesso em: 26 jan. 2014.

ANGELSEN, A. Policies for reduced deforestation and their impact on agricultural production. Proceedings of the National Academy of Sciences of the United States of America, v. 107, n. 46, p. 19639-44, 16 nov. 2010. Disponivel em: <http://www.pubmedcentral.nih.gov/ articlerender.fcgi ?artid $=2993393 \&$ tool $=$ pmcentrez\&rendertype=abstract $>$. Acesso em: 21 jan. 2014.

ASSUNÇÃO, J.; GANDOUR, C.; ROCHA, R. DETERring Deforestation in the Brazilian Amazon: Environmental Monitoring and Law enforcement. Rio de Janeiro: [s.n.], 2013. Disponível em: $<$ http://climatepolicyinitiative.org/brazil/files/2013/05/DETERring-Deforestation-in-theBrazilian-Amazon-Technical-Paper-Only-\%E2\%80\%93-English.pdf>. Acesso em: 11 set. 2014.

ARTHUR, W. B. Competing Technologies, Increasing Returns, and lock-in by Historical Events. The Economic Journal, v. 99, n. 394, 1989. p. 116-131.

ARTHUR, W. B. Designing Economic Agents that Act like Human Agents: A Behavioral Approach to Bounded Rationality. American Economic Review (A.E.A. Papers and Proc.), v. 81, p. 353-359, 1991. 
BANDINI, S.;MANZONI, S.; VIZZARI, G. Agent Based Modeling and Simulation: An Informatics Perspective. Journal of Artificial Societies and Social Simulation, v. 12, n.4, 2009.

BOLTZ, F.; HOLMES, T. P.; CARTER, D. R. Economic and environmental impacts of conventional and reduced-impact logging in Tropical South America: a comparative review. Forest Policy and Economics, v. 5, n. 1, p. 69-81, jan. 2003. Disponível em: <http://linkinghub.elsevier.com/retrieve/pii/S1389934101000752>.

BOSCOLO, M.; BUONGIORNO, J.; PANAYOTOU, T. Theory and Applications Simulating options for carbon sequestration tropical rainforest. v. 2, p. 241-263, 1997.

BOSCOLO, M.; VINCENT, J. R. Area fees and logging in tropical timber concessions. Environment and Development Economics, v. 12, n. 04, p. 505, 25 jul. 2007. Disponível em: <http:// www.journals.cambridge.org/abstract_S1355770X0700366X>. Acesso em: 3 jun. 2014.

BOSCOLO, M.; VINCENT, J. R. Better Logging Practices in Promoting Analysis of Tropical Forests: A Simulation Alternative Regulations. v. 76, n. 1, p. 1-14, 2000.

BOSCOLO, M.; VINCENT, J. R. Nonconvexities in the production of timber, biodiversity, and carbon sequestration. Journal of Environmental Economics and Management, v. 46, n. 2, p. 251-268, set. 2003. Disponível em: <http://linkinghub.elsevier.com/retrieve/pii/ S0095069602000347>. Acesso em: 3 jun. 2014.

BRITO, B.; BARRETO, P. Enforcement against illegal logging in the Brazilian Amazon. In: PADDOCK, L. Compilance and enforcement in Environmental Law. Cheltenham Glos: Edward Elgard Publisging, 2011.

COE, M. T. et al. Deforestation and climate feedbacks threaten the ecological integrity of south - southeastern Amazonia. 2013.

CONRAD, R. F; GILLIS, M.; MERCER, D. E.. Tropical forest harvesting and taxation: a dynamic model of harvesting behavior under selective extraction systems. Environment and Development Economics, v. 10, 2005, p. 689-709.

DOSI, G.; NELSON, R. R. Evolutionary Economics An introduction to evolutionary theories in economics. p. 153-172, 1994.

DOSI, G.. Mudança Técnica e Transformação Industrial. Campinas: Unicamp, 2006.

FABER, A.; FRENKEN, K. Models in evolutionary economics and environmental policy: Towards an evolutionary environmental economics. Technological Forecasting and Social Change, v. 76, n. 4, p. 462-470, maio 2009. Disponível em: <http://linkinghub.elsevier. com/retrieve/pii/S004016250800084X>. Acesso em: 5 out. 2012.

FEARNSIDE, P.M. Recursos madeireiros na Amazônia brasileira: Impactos e sustentabilidade da exploração. In: VAL, A.L.; SANTOS, G. M. dos (Eds.) Grupo de Estudos Estratégicos Amazônicos (GEEA) Tomo 3. Instituto Nacional de Pesquisas da Amazônia (INPA), Manaus, Amazonas, 2010.

GARCÍA-FERNÁNDEZ, C.; RUIZ-PÉREZ, M.; WUNDER, S. Is multiple-use forest management widely implementable in the tropics? Forest Ecology and Management, v. 256, n. 7, p. 1468-1476, set. 2008. Disponível em: <http://linkinghub.elsevier.com/retrieve/pii/ S0378112708003721 >. Acesso em: 21 jan. 2014.

GILBERT, N.; TERNA, P. How to build and use agent-based models in social science. Mind \& Society, v. 1, n. 1, p. 57-72, mar. 2000. Disponível em: <http://link.springer.com/10.1007/ 
BF02512229>.

GUTIERREZ-VELEZ, V. H.; MACDICKEN, K. Quantifying the direct social and governmental costs of illegal logging in the Bolivian, Brazilian, and Peruvian Amazon. Forest Policy and Economics, v. 10, n. 4, p. 248-256, fev. 2008. Disponível em: <http://linkinghub.elsevier. com/retrieve/pii/S138993410700072X>. Acesso em: 3 jun. 2014.

KARSENTY, A. Forest taxation regime for tropical forests: lessons from Central Africa. International Forestry Review, v. 12, n. 2, p. 121-129, jun. 2010. Disponível em: <http://www. ingentaconnect.com/content/cfa/ifr/2010/00000012/00000002/art00001>.

KLIMAS, C. A. et al. Viability of combined timber and non-timber harvests for one species: A Carapa guianensis case study. Ecological Modelling, v. 246, p. 147-156, nov. 2012. Disponível em: <http://linkinghub.elsevier.com/retrieve/pii/S0304380012003535>. Acesso em: 3 jun. 2014.

LAMBIN, E. F.; GEIST, H. J.; LEPERS, E. D Ynamics of L and -U Se and L and -C Over C Hange in T Ropical R Egions. Annual Review of Environment and Resources, v. 28, n. 1, p. 205-241, nov. 2003. Disponível em: <http://www.annualreviews.org/doi/abs/10.1146/annurev. energy.28.050302.105459>. Acesso em: 26 jan. 2014.

MACPHERSON, A. J. et al. A Model for comparing reduced impact logging with conventional logging for an Eastern Amazonian Forest. Forest Ecology and Management, v. 260, n. 11, p. 2002-2011, nov. 2010. Disponível em: <http://inkinghub.elsevier.com/retrieve/ pii/S0378112710005219>. Acesso em: 26 jan. 2014.

MACPHERSON, A. J. et al. The sustainability of timber production from Eastern Amazonian forests. Land Use Policy, v. 29, n. 2, p. 339-350, abr. 2012. Disponível em: <http://linkinghub.elsevier.com/retrieve/pii/S026483771100072X>. Acesso em: 26 jan. 2014.

MERRY, F. et al. Balancing conservation and economic sustainability: the future of the Amazon timber industry. Environmental management, v. 44, n. 3, p. 395-407, set. 2009. Disponível em: <http://www.ncbi.nlm.nih.gov/pubmed/19636609>. Acesso em: 26 jan. 2014.

NEPSTAD, D. et al. Environment. The end of deforestation in the Brazilian Amazon. Science (New York, N.Y.), v. 326, n. 5958, p. 1350-1, 4 dez. 2009. Disponível em: <http://www. ncbi.nlm.nih.gov/pubmed/19965742>. Acesso em: 26 jan. 2014.

NEPSTAD, D. C. et al. Interactions among Amazon land use, forests and climate: prospects for a near-term forest tipping point. Philosophical transactions of the Royal Society of London. Series B, Biological sciences, v. 363, n. 1498, p. 1737-46, 27 maio 2008. Disponível em: $<$ http://www.pubmedcentral.nih.gov/articlerender.fcgi?artid=2373903\&tool=pmcentrez \&rendertype=abstract $>$. Acesso em: 23 jan. 2014.

PEARCE, D.; PUTZ, F. E.; VANCLAY, J. K. Sustainable forestry in the tropics: panacea or folly? Forest Ecology and Management, v. 172, n. 2-3, p. 229-247, jan. 2003. Disponível em: $<$ http://linkinghub.elsevier.com/retrieve/pii/S0378112701007988>.

PEREIRA, D.; SANTOS, D.; VEDOVETO, M.. GUIMARÃES, J.; VERÍSSMO, A. Fatos florestais da Amazônia 2010. Belém: Imazon, 2010.

ROS-TONEN, Mirjam A. F. Et al. Forest-related partnerships in Brazilian Amazonia: There is more to sustainable forest management than reduced impact logging. Forest Ecology and Management. v. 256, 2008, p. 1482-1497. 
SCHUMPETER, J. A.. Teoria do Desenvolvimento Econômico: uma investigação sobre lucros, capital, crédito, juro e ciclo econômico. São Paulo: Nova Cultural, 1997.

SIST, P.; FERREIRA, F. N. Sustainability of reduced-impact logging in the Eastern Amazon. Forest Ecology and Management, v. 243, n. 2-3, p. 199-209, maio 2007. Disponível em: $<$ http://linkinghub.elsevier.com/retrieve/pii/S0378112707001582>. Acesso em: 26 jan. 2014.

TESFATSION, L. Agent-Based Computational Economics: Growing Economies from the Bottom Up. n. October 2001, p. 1-31, 2002.

TOBIAS, R.; HOFMANN, C. Evaluation of free Java-libraries for social-scientific agent based simulation. Journal of Artifical Societies and Social Simulation, v. 7, n.1, 2004.

VALLE, D. et al. Adaptation of a spatially explicit individual tree-based growth and yield model and long-term comparison between reduced-impact and conventional logging in eastern Amazonia, Brazil. Forest Ecology and Management, v. 243, n. 2-3, p. 187-198, maio 2007. Disponível em: <http://linkinghub.elsevier.com/retrieve/pii/S0378112707001417>. Acesso em: 26 jan. 2014.

VAN DEN BERGH, J. C. J. M. et al. Survival of the greenest: evolutionary economics and policies for energy innovation. Environmental Sciences, v. 3, n. 1, p. 57-71, mar. 2006. Disponível em: <http://www.tandfonline.com/doi/abs/10.1080/15693430500481295>. Acesso em: 11 set. 2014.

YOUSEFPOUR, R.; HANEWINKEL, M. Modelling of forest conversion planning with an adaptive simulation-optimization approach and simultaneous consideration of the values of timber, carbon and biodiversity. Ecological Economics, v. 68, n. 6, p. 1711-1722, abr. 2009. Disponível em: <http://linkinghub.elsevier.com/retrieve/pii/S0921800908005351>. Acesso em: 26 jan. 2014.

ZARIN, D. J. et al. Beyond reaping the first harvest: management objectives for timber production in the Brazilian Amazon. Conservation biology: the journal of the Society for Conservation Biology, v. 21, n. 4, p. 916-25, ago. 2007. Disponível em: <http://www.ncbi. nlm.nih.gov/pubmed/17650242>. Acesso em: 21 jan. 2014.

\footnotetext{
About the authors

Hilder André Bezerra Farias - hilder@ufpa.br

Universidade Federal do Pará, Belém, Pará.

Sérgio Luiz de Medeiros Rivero-sergiolmrivero@gmail.com

Universidade Federal do Pará, Belém, Pará.

Márcia Jucá Teixeira Diniz-mjucadiniz@ufpa.br

Universidade Federal do Pará, Belém, Pará.

This research received financial support from Rede Biomassa Florestal project, which is financed by the Research Support Foundation of the State of Pará (FAPESPA), Edict 014/2008. This present article was elaborated as part of the Postgraduate Economics Program of Pará Federal University (PPGE/UFPA), with the aid of its resources.
}

\section{About the article}

Submission received on January 05, 2015. Approved for publication on October 02, 2016. 